Article

\title{
Expanding Plasma Process for Nitriding Mo-Ti Bilayer Thin Films
}

\author{
Isabelle Jauberteau ${ }^{1, *}$, Richard Mayet ${ }^{1}$, Julie Cornette ${ }^{1}$, Pierre Carles ${ }^{1}$, Denis Mangin ${ }^{2}$, \\ Annie Bessaudou ${ }^{3}$, Jean Louis Jauberteau ${ }^{1}$ and Armand Passelergue ${ }^{3}$ \\ 1 Faculté des Sciences et Techniques, Université de Limoges, CNRS, UMR7315, IRCER, CEC, 12 Rue Atlantis, \\ F-87068 Limoges, France; richard.mayet@unilim.fr (R.M.); julie.cornette@unilim.fr (J.C.); \\ pierre.carles@unilim.fr (P.C.); jean-louis.jauberteau@unilim.fr (J.L.J.) \\ 2 Institut Jean Lamour, CNRS, UMR7198, Université de Lorraine, Site ARTEM, 2 allée A. Guinier, \\ F-54011 Nancy, France; denis.mangin@univ-lorraine.fr \\ 3 Faculté des Sciences et Techniques, Université de Limoges, CNRS, XLIM, UMR6172, 123 av. A. Thomas, \\ F-87060 Limoges, France; annie.bessaudou@unilim.fr (A.B.); armand.passelergue@unilim.fr (A.P.) \\ * Correspondence: isabelle.jauberteau@unilim.fr; Tel.: +33-58-750-2323
}

Received: 14 December 2018; Accepted: 31 January 2019; Published: 5 February 2019

\begin{abstract}
Owing to the reducing effect of $\mathrm{NH}_{x}$ radicals and $\mathrm{H}$ species produced in $\left(\mathrm{Ar}-\mathrm{N}_{2}-\mathrm{H}_{2}\right)$ expanding plasma, chemical reactions are promoted in thin metal films in contrast with other plasma treatments where the impinging energetic ions play the main role. Multi layers of $\mathrm{Mo}, \mathrm{Ti}$, and their nitrides are used in very recent applications such as supercapacitors or solar cells. They combine the interesting properties of the constituents. This work reports on the formation and the structure of $\mathrm{Ti}$ nitrides and Mo silicides in Mo-Ti bilayer films coated on Si wafers exposed to $\left(\mathrm{Ar}-\mathrm{N}_{2}-\mathrm{H}_{2}\right)$ plasma for 1 to $3 \mathrm{~h}$. Nitrogen diffuses into the surface layers from $400{ }^{\circ} \mathrm{C}$ and TiN starts to crystallize from $600{ }^{\circ} \mathrm{C}$. Interdiffusion of Mo, Ti, and Si through Mo-Ti bilayer films gives rise to the formation of Mo-Ti alloys and $\mathrm{MoSi}_{2}$ of hexagonal structure, which transforms into $\mathrm{MoSi}_{2}$ of tetragonal structure at longer treatment durations. A $1 \mathrm{~h} 30 \mathrm{~min}$ plasma exposure at $800{ }^{\circ} \mathrm{C}$ leads to the formation of three layers of nearly equal thickness with clear interfaces, which consist of $\mathrm{TiN}$ and $\mathrm{MoSi}_{2}$ of nanometric size in the vicinity of the Mo-Ti bilayer film surface.
\end{abstract}

Keywords: Mo-Ti bilayer films; expanding plasma; Ti nitrides; Mo silicides; X-ray diffraction; Raman spectroscopy; secondary ion mass spectrometry; transmission electron microscopy; scanning electron microscopy

\section{Introduction}

Transition metal nitrides and silicides exhibit very attractive physical and chemical properties. Owing to their structure which involves covalent, ionic, and metallic bonding, the high hardness, Young modulus, and melting point equal to $2947^{\circ} \mathrm{C}$ for TiN, make them similar to ceramic materials, whereas their low electrical resistivity equal to $19.8 \mu \Omega \cdot \mathrm{cm}$ for $\mathrm{Mo}_{2} \mathrm{~N}$ and $30 \mu \Omega \cdot \mathrm{cm}$ for TiN make them similar to metals [1-3]. In the same way, transition metal silicides also exhibit low resistivity equal to $14-17 \mu \Omega \cdot \mathrm{cm}$ for $\mathrm{TiSi}_{2}$ [4]. A low value of about $40 \mu \Omega \cdot \mathrm{cm}$ has also been found for molybdenum silicide films with Si/Mo ratio equal to about 1 [5]. Transition metal silicides also have high temperature stability, chemical compatibility, and low Schottky barrier height. Transition metal nitrides and silicides are used in a large range of applications. They can replace conventional polysilicon as gate electrodes and interconnects in metal oxide semiconductor (MOS) devices [6]. The barrier height of $\mathrm{TiN} / \mathrm{TiSi}_{x} / \mathrm{Si}$ systems is lowered by $80 \mathrm{meV}$ compared with $\mathrm{TiSi}_{x} / \mathrm{Si}$ Schottky diodes, which results in $15 \%$ of self-power consumption saving [7]. Multilayer films of transition metal nitrides, with layer thickness ranging from ten to 
hundreds of nanometers, allow beneficial properties of constituting materials to be combined [8]. Ti-Mo multilayers have attracted much interest in a wide range of applications. $\mathrm{MoN}_{x} / \mathrm{TiN}$ systems have been recently investigated for their enhanced electron transportation capability, capacitance, and high cycling stability which make them valuable as supercapacitor electrode material for energy storage $[9,10]$. TiN films are also good diffusion barrier layers. High efficiency CIGS $\left(\mathrm{Cu}(\mathrm{In}, \mathrm{Ga}) \mathrm{Se}_{2}\right)$ solar cells can be obtained by introducing a thin TiN film between Mo back electrode and the soda lime glass substrate [11,12]. TiN films prevent Na diffusion from the soda lime glass into the CIGS absorber via the Mo contact [12].

Films of metal nitrides are mainly deposited by vacuum arc evaporation [8], direct current (DC) or radio frequent $(\mathrm{RF})$ magnetron reactive sputtering [6,11]. A review of deposition methods of thin films is reported in [2]. In this work, the thermochemical treatment of thin metal films is carried out in expanding plasma of $\left(\mathrm{Ar}-\mathrm{N}_{2}-\mathrm{H}_{2}\right)$ gas mixtures activated by microwaves of $2.45 \mathrm{GHz}$. The high degree of ionization and dissociation makes the microwave plasma very attractive compared with other types of electrical excitations. In contrast with most plasma treatments, the sputtering of the surface of materials by the impinging energetic ions, as well as the heating effect, is trifling. The reducing effect of passive surface layers, which remain on materials such as oxides and carbides, is carried out by hydrogen species such as $\mathrm{NH}_{x}$ and/or $\mathrm{H}$ produced in $\left(\mathrm{Ar}-\mathrm{N}_{2}-\mathrm{H}_{2}\right)$ plasma. This process promotes chemical reactions on the surface of metal films. A reduction-nitridation process has been evidenced in Mo thin films processed in expanding plasma [13]. Exothermic reactions produced between hydrogen species and oxides remaining in Mo film, promote the formation of the high temperature $\gamma \mathrm{Mo}_{2} \mathrm{~N}$ phase to the detriment of the low temperature $\beta \mathrm{Mo}_{2} \mathrm{~N}$ phase. In the same way, a competing process leading to the gradual conversion of $\mathrm{TiSi}_{2}$ into $\mathrm{TiN}$, in accordance with the values of the respective enthalpy of formation, has been investigated in Ti thin films exposed to $\left(\mathrm{Ar}-\mathrm{N}_{2}-\mathrm{H}_{2}\right)$ plasma [14]. In this work, the formation of nitrides and silicides in Mo-Ti bilayer films is analyzed by way of various investigation means. This work is especially focused on the crystallization and growth of various phases such as Ti nitrides and Mo silicides due to the intensive diffusion of N, Si, Ti, and Mo through the Mo-Ti bilayer films. The results are compared with those previously obtained in Mo and Ti thin films.

\section{Materials and Methods}

\subsection{Conditions of Formation of an Expanding Plasma}

The experiments are carried out in the reactor displayed in Figure 1.

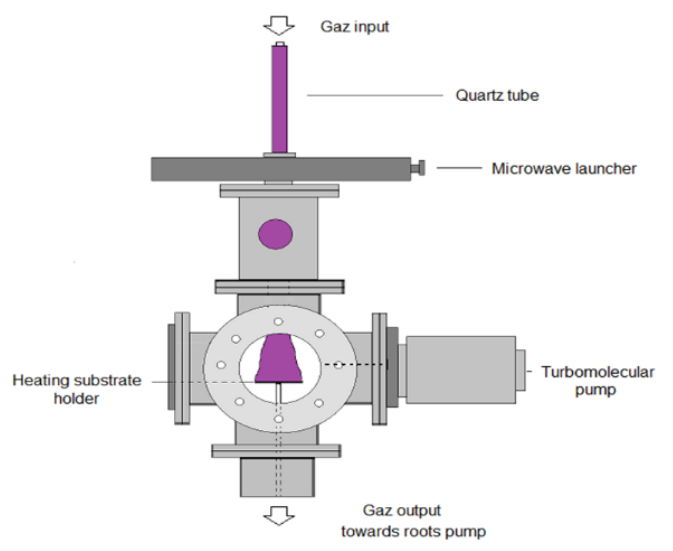

Figure 1. Experimental set-up [15].

The plasma is ignited in $\left(\mathrm{Ar}-\mathrm{N}_{2}-\mathrm{H}_{2}\right)$ gas mixtures by a microwave discharge which is produced by means of a SAIREM GMP $12 \mathrm{kE}$ power supply operating up to $1.2 \mathrm{kV}$ at a frequency of $2.45 \mathrm{GHz}$ in a fused silica tube (external and internal diameter of 24 and $20 \mathrm{~mm}$, respectively) passing through the surface wave launcher. The power of the electromagnetic wave is mainly transferred to electrons and 
then to other gaseous species by collisions. The plasma is expanded out of the center of the discharge into the stainless steel vessel up to the surface of the substrate, under the conditions of a high density of electrons. These conditions depend on the microwave frequency as well as the frequency of collisions occurring in the plasma. The electron density is equal to $1.68 \times 10^{16} \mathrm{~m}^{-3}$ in pure Ar plasma at $2 \mathrm{~cm}$ from the discharge tube exit, at a microwave power of $400 \mathrm{~W}$ [13]. The addition of molecular gas in $\mathrm{Ar}$ results in a decrease of electron density with increasing collisions between electrons and molecules. The electron density is about 5 times lower in $\left(\mathrm{Ar}-50 \% \mathrm{~N}_{2}\right)$ and pure $\mathrm{N}_{2}$ plasma. It is equal to about $2.78 \times 10^{14} \mathrm{~m}^{-3}$ in $\left(\mathrm{Ar}-31 \% \mathrm{~N}_{2}-6 \% \mathrm{H}_{2}\right)$ plasma used in this study. The electron density tends to decrease at a larger distance from the discharge tube exit. $\left(\mathrm{Ar}-\mathrm{N}_{2}-\mathrm{H}_{2}\right)$ plasma mainly produce $\mathrm{Ar}^{+}$ions and reactive species such as $\mathrm{NH}_{x}$ radicals. The density of Ar is equal to about $2 \times 10^{22} \mathrm{~m}^{-3}$. This value is about 100 times larger than those of $\mathrm{NH}_{3}$ and $\mathrm{NH}_{2}$ radicals and about $10^{3}$ and $10^{4}$ larger than $\mathrm{NH}$ and $\mathrm{N}$ radicals. The flux of $\mathrm{Ar}^{+}$ions is equal to about $7 \times 10^{18} \mathrm{~m}^{2} \cdot \mathrm{s}^{-1}$. The electron and ion energies are equal to $0.51-1.37 \mathrm{eV}$ and $0.1 \mathrm{eV}$, respectively. Since the ion energy is very low, plasma species such as $\mathrm{NH}_{x}$ and $\mathrm{H}$ species play the main role during the process. They react at the surface of the substrate and thus promote the transfer of active species into the surface layers. Under the condition of wave propagation, the plasma expanded out of the center of the discharge forms a bright cone from the quartz tube exit up to the heating substrate holder (Figure 1). The plasma treatment process is optimized by moving the substrate holder relative to the center of the discharge along the vertical axis. In this work, the experiments are made in $\left(\mathrm{Ar}-31 \% \mathrm{~N}_{2}-6 \% \mathrm{H}_{2}\right)$ at $12.5 \mathrm{~cm}$ from the center of the discharge at a microwave power of $500 \mathrm{~W}$.

\subsection{Deposition of Thin Films}

Mo and Ti films are successively deposited on $\mathrm{Si}(100)$ wafers in an electron beam evaporator filled with Ar gas (alphagas $\mathrm{N}_{50} \mathrm{H}_{2} \mathrm{O}<3$ ppm, $\mathrm{O}_{2}<2$ ppm and $\mathrm{C}_{n} \mathrm{H}_{m}<0.5 \mathrm{ppm}$ ) at a pressure of $0.5 \mathrm{~Pa}$. Pure Mo and Ti cylinders and pellets (99.95\%) are used. Si wafers are biased at $-400 \mathrm{~V}$ and heated at $400{ }^{\circ} \mathrm{C}$. Under such conditions, the surface is cleaned by impinging ions that improve the adhesion of films on substrates. The thickness of Mo and Ti films, equal to $250 \mathrm{~nm}$ each, is controlled by a quartz balance. The resulting samples of final dimensions equal to about $10 \times 10 \mathrm{~mm}^{2}$ are cut from wafers.

\subsection{Plasma Nitriding Process}

Mo-Ti bilayer films are placed on the heating substrate holder. The vacuum chamber is then evacuated to a pressure of $10^{-5} \mathrm{~Pa}$. The heating is switched on up to 400,600 , and $800^{\circ} \mathrm{C}$. Once the temperature is reached, $\left(\mathrm{Ar}-31 \% \mathrm{~N}_{2}-6 \% \mathrm{H}_{2}\right)$ gas mixture is introduced into the chamber. The discharge is produced at a microwave power of $500 \mathrm{~W}$ and a total pressure of $0.13 \mathrm{kPa}$. The experiments are run for $1 \mathrm{~h}, 1 \mathrm{~h} 30 \mathrm{~min}$, and $3 \mathrm{~h}$.

\subsection{Investigations of Mo-Ti Bilayer Films}

The phase composition and crystal structures of the compounds are examined by X-ray diffraction (XRD) and Raman spectroscopy. XRD measurements are carried out in a D8 Advance Bruker diffractometer (Karlsruhe, Germany) using a primary monochromator to select $\mathrm{CuK} \alpha 1$ radiation and a Lynx-eye position sensitive detector ( $3.4^{\circ}$ for fast acquisition). The configuration of the system is the classical Bragg-Brentano geometry. Raman spectra are recorded in backscattering geometry by using a HORIBA-JOBIN-YVON T 64000 model spectrometer (Villeneuve d'Ascq, France), equipped with a charged coupled device (CCD) camera cooled by a flux of liquid $\mathrm{N}_{2}$ up to $-133^{\circ} \mathrm{C}$, to reduce thermal noise. The exciting line, of a wavelength equal to $514.532 \mathrm{~nm}$, is produced by an $\mathrm{Ar}^{+}$laser and focused onto the sample, via a $\times 50$-long working distance objective, resulting in a spot of diameter equal to $1 \mu \mathrm{m}$. The power of the laser is modified to protect the sample from any damage. The spectra are averaged to make the signal intensities representative of the samples. The diffusion profiles of elements are established by secondary ion mass spectrometry (SIMS) in an IMS7F CAMECA spectrometer (Gennevilliers, France), which is conducted using cesium ions $\left(\mathrm{Cs}^{+}\right)$with a primary voltage and 
intensity of $5 \mathrm{kV}$ and $25 \mathrm{nA}$, respectively. The primary beam is scanned over an area of $200 \mu \mathrm{m} \times$ $200 \mu \mathrm{m}$. The results are normalized with respect to the cesium signal. The structure, the crystalline phases, interfaces, and microstructures are investigated by transmission electron microscopy (TEM) and selected area electron diffraction (SAED) in a 2100F JEOL microscope (Tokyo, Japan). Chemical composition of films are analyzed by nano-probe energy dispersive spectrometry (EDS) in the 2100F JEOL microscope (Tokyo, Japan). Cross sectional samples are prepared by mechanical polishing and subsequently thinned by argon ion milling, before they are analyzed. The morphology of the surface is measured by means of scanning electron microscopy (SEM) in a Zeiss crossbeam 550 model $(\mathrm{GmbH}$, Oberkochen, Germany).

\section{Results}

\subsection{Mo-Ti Interface Formation of Mo-Ti Solid Solution}

The X-ray diffraction pattern corresponding to the untreated Mo-Ti film only displays the most intense reflection lines of atomic planes of pure Mo of body-centered cubic structure at $2 \theta$ Bragg angles equal to $40.52^{\circ}$ and $73.68^{\circ}$ (JCPDS card no. 42.1120) (Figure 2).

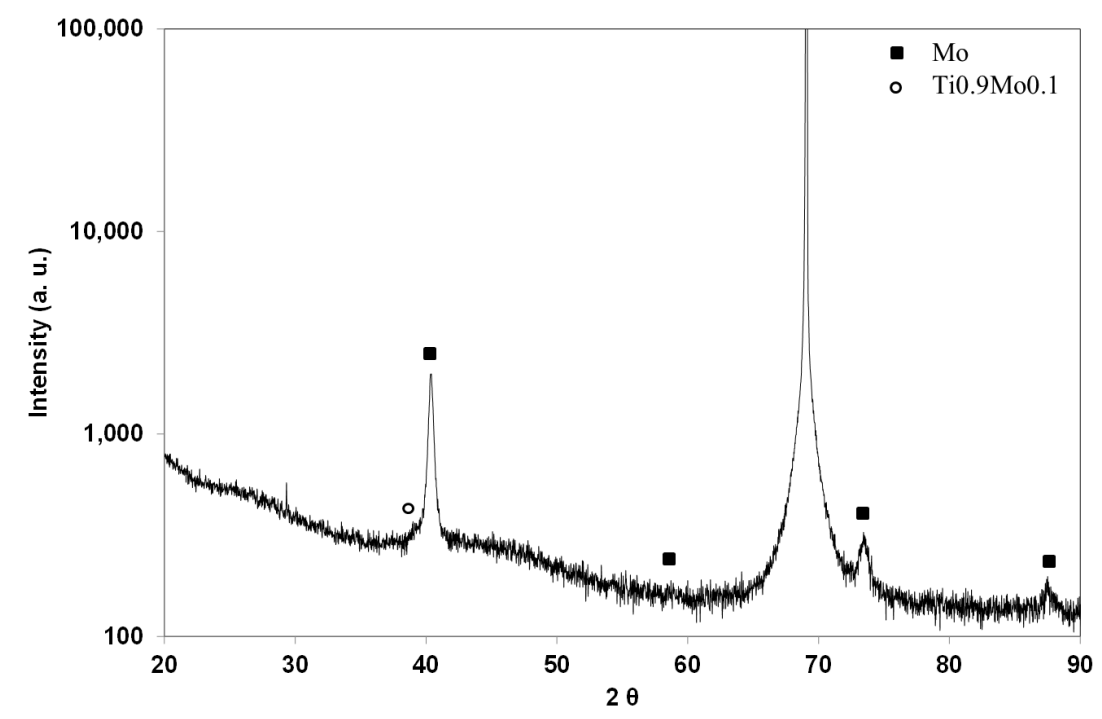

Figure 2. X-ray diffraction pattern of untreated Mo-Ti, $250-250 \mathrm{~nm}$, thick bilayer film.

No trace of Ti metal is detected. The other intense diffraction peak at $69^{\circ}$ corresponds to the $\mathrm{Si}$ substrate (JCPDS card no. 01-7247). Previous investigations performed on pure Ti thin films coated on Si wafers, and using the same method, resulted in XRD patterns displaying the features of Ti of hexagonal-close packed structure. The most intense diffraction line is close to the one of Mo at $40.52^{\circ}$. However, since the peak assigned to Mo seems quite symmetrical, we can conclude that Ti does not crystallize in hexagonal structure in Ti-Mo bilayer films and/or Mo is much more crystallized than Ti. The second assumption is consistent with a recent study. Xin et al. [16] have deposited a Ti-Mo bilayer on $\mathrm{Al}_{2} \mathrm{O}_{3}$ ceramic by magnetron sputtering. The thicknesses of Mo and Ti films are close to those that were used in the present work. The corresponding XRD pattern reported in [16] only shows a tiny peak corresponding to Ti of hexagonal structure close to a very intense Mo peak. The large intensity difference has been assigned to a better crystallization of Mo. In the present work, a thorough examination of the XRD pattern (Figure 2) allows us to see a tiny peak located at a Bragg angle equal to about $39.1^{\circ}$. It is worth noting that pure Ti crystallizes in another allotropic form of body-centered cubic structure similar to Mo, which is named $\beta$-phase, in contrast with $\alpha$-phase of hexagonal structure, stable at room temperature. The transformation of the $\alpha$-phase into $\beta$-phase occurs at $1155 \mathrm{~K}$ [17]. However, the addition of Mo promotes the stability of the $\beta$-phase at room temperature. Mo is slightly soluble in $\alpha$-Ti, whereas $\beta$-Ti forms a continuous series of solid solutions with Mo, according to the 
Mo-Ti phase diagram [18]. The microstructure of Ti varies with Mo content: The $\alpha$-phase of low Mo content consists of an arrangement of regular lamellae, whereas the $\beta$-phase is identified as an arrangement of large grains. The Bragg angle $2 \theta=39.1^{\circ}$ corresponds to the most intense reflection line of $\mathrm{Ti}_{0.9} \mathrm{Mo}_{0.1}$ solid solution of body-centered cubic structure, with a lattice parameter $a=0.3257 \mathrm{~nm}$ (JCPDS card no. 04-018-6034). In their very recent article, Kislitin et al. 2018 [19] fitted the lattice parameter of $\beta$-Ti-Mo solid solutions versus at.\% of Mo to a Vegard's law. They found a strong negative departure of the function compared to the Vegard's law which is assigned to a strong lattice compression. According to Vegard's law, the lattice parameter of $0.325 \mathrm{~nm}$ should correspond to a Mo content of about 35 at. $\%$. The formation of $\mathrm{Ti}_{0.9} \mathrm{Mo}_{0.1}$ solid solution is consistent with other results found in the literature, since it is reported that Ti-Mo solid solutions, with Mo content larger than $8-10$ at. $\%$, crystallize in $\beta$-Ti structure with an intense reflection line at about $39^{\circ}$. The other XRD peaks are only slightly intense [20-22].

So, we can conclude that the lack of $\alpha$-Ti phase in XRD patterns can be correlated to the formation of $\beta$-Ti-Mo alloys, during the deposition of Mo-Ti bilayers on $\mathrm{Si}$ wafers by evaporation. However, the growth of epitaxial Ti films on $\mathrm{Mo}$ surface or $\mathrm{TiO}_{2}$ cannot be ruled out. In what follows, investigations on the diffusion profiles corresponding to elements contained in Ti-Mo bilayers and carried out by SIMS, will help us to clear up this phenomenon. Owing to the high sensitivity and excellent separation power of SIMS method, the evolution of the SIMS signal of various elements contained in films versus process temperature is well identified. Quantitative analysis may only be conducted through relative measurements by using a calibration factor for most elements. The diffusion profiles of $\mathrm{Si}, \mathrm{Ti}, \mathrm{Mo}, \mathrm{C}$, $\mathrm{N}$, and $\mathrm{O}$ are displayed in Figure 3.

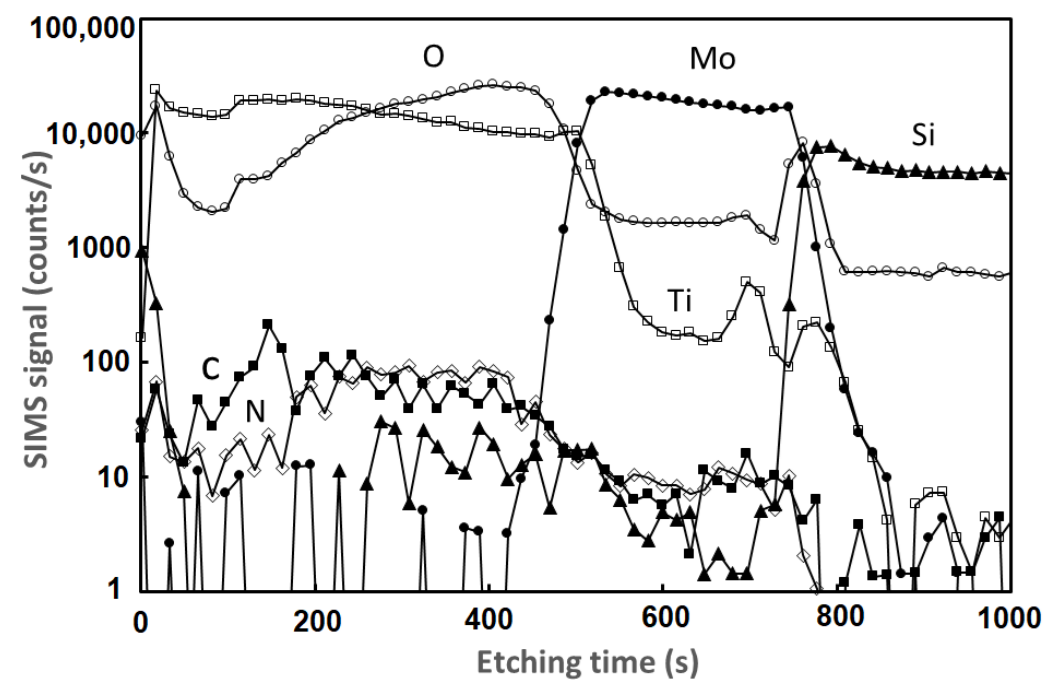

Figure 3. SIMS depth profiles of as-deposited Mo-Ti bilayer films.

The Mo-Si interface is well identified for a sputtering time of about $800 \mathrm{~s}$. The Mo-Ti interface is still identified; however, Ti has diffused into the whole Mo film thickness up to the Mo-Si interface. So, Mo-Ti alloys are formed. Such a result was obtained in a recent study on the formation of a Mo-Ti layer with a Ti content gradient, in $\mathrm{Ti} / \mathrm{Mo} / \mathrm{Yb}_{0.3} \mathrm{Co}_{4} \mathrm{Sb}_{12}$ thermoelectric joints heated at $550{ }^{\circ} \mathrm{C}$ in vacuum [23]. As also seen in Figure 3, the nitrogen and carbon signals are low in the as-deposited Ti-Mo bilayer. In contrast, the oxygen signal is high. Oxygen has been incorporated in the Ti-Mo bilayer during the evaporation of metals. Since $\mathrm{Ti}$ is very reactive towards oxygen, the formation $\mathrm{TiO}_{2}$ of amorphous structure, in addition to Mo-Ti alloys, can be expected during the evaporation process.

In what follows, the formation and growth of $\mathrm{TiN}$ and $\mathrm{MoSi}_{2}$ crystallized phases in Mo-Ti bilayer films coated on Si substrates, heated at 600 and $800{ }^{\circ} \mathrm{C}$ and exposed to $\left(\mathrm{Ar}-31 \% \mathrm{~N}_{2}-6 \% \mathrm{H}_{2}\right)$ plasma for $1 \mathrm{~h} 30 \mathrm{~min}$ and $3 \mathrm{~h}$, have been investigated by XRD and Raman spectroscopy. 


\subsection{Formation of TiN and $\mathrm{MoSi}_{2}$ in Mo-Ti Bilayer Films Processed in Expanding Plasma}

\subsubsection{XRD Investigations}

TiN starts to crystallize at $600{ }^{\circ} \mathrm{C}$. The tiny features detected at Bragg angles of $36.8^{\circ}$ and $42.6^{\circ}$ are assigned to the most intense (111) and (200) reflection lines of the TiN phase of cubic structure (JCPDS card no. 04-004-2917) (Figure 4a).

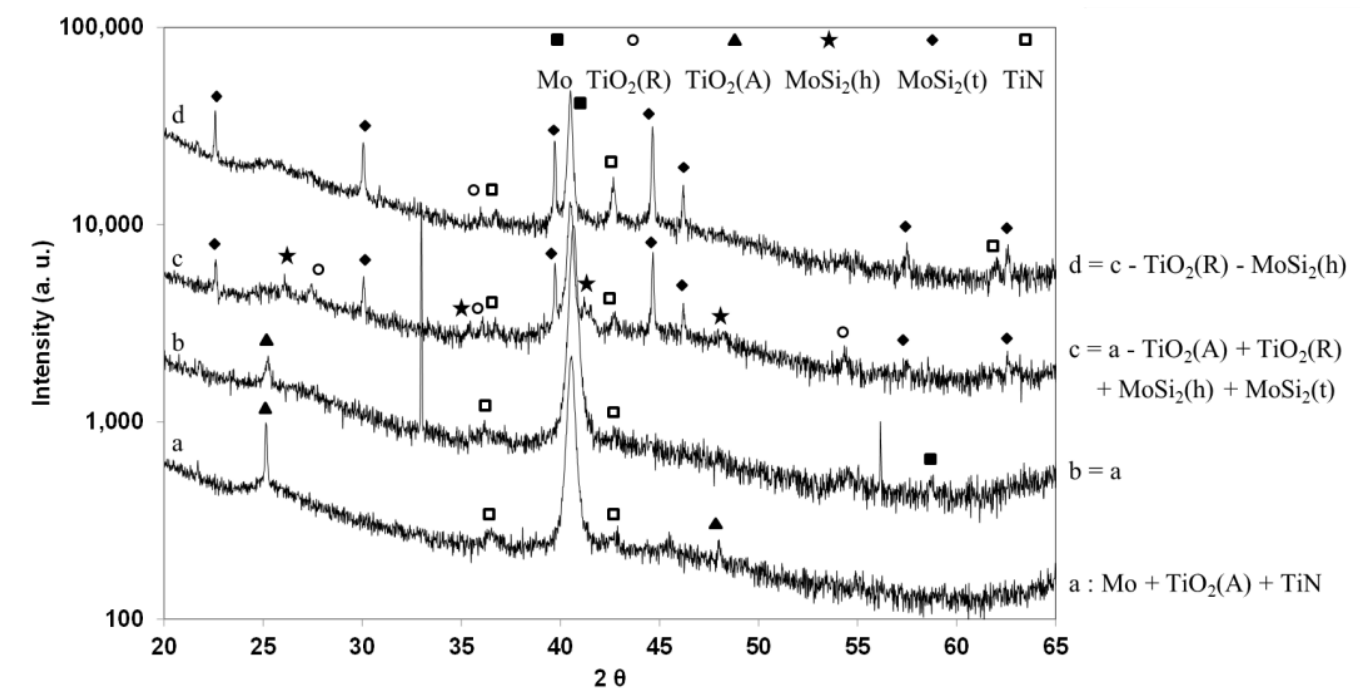

Figure 4. X-ray diffraction patterns of Mo-Ti bilayer films heated at $600{ }^{\circ} \mathrm{C}$ and exposed to $\left(\mathrm{Ar}-31 \% \mathrm{~N}_{2}\right.$ $\left.6 \% \mathrm{H}_{2}\right)$ for $1 \mathrm{~h} 30 \mathrm{~min}(\mathrm{a}), 3 \mathrm{~h}(\mathbf{b})$, heated at $800{ }^{\circ} \mathrm{C}$ and exposed to $\left(\mathrm{Ar}-31 \% \mathrm{~N}_{2}-6 \% \mathrm{H}_{2}\right)$ plasma for $1 \mathrm{~h}$ $30 \mathrm{~min}(\mathbf{c})$ and $3 \mathrm{~h} \mathrm{(d)}$.

Since the XRD peaks are broad and slightly intense, TiN consists of small crystallites. The other reflection lines located at Bragg angles equal to $25^{\circ}$ and $43^{\circ}$ correspond to the anatase phase of $\mathrm{TiO}_{2}$. Compared with $\mathrm{TiN}, \mathrm{TiO}_{2}$ is well crystallized. Ti metal, which strongly reacts with oxygen to form $\mathrm{TiO}_{2}$ of amorphous structure during the evaporation process, crystallizes during the plasma process. A longer exposure time up to $3 \mathrm{~h}$ results in a decrease of both $\mathrm{TiN}$ and $\mathrm{TiO}_{2}$ reflection line intensities (Figure $4 b)$. Hydrogen species as $\mathrm{NH}_{x}$ radicals and/or $\mathrm{H}$ atoms produced in $\left(\mathrm{Ar}-\mathrm{N}_{2}-\mathrm{H}_{2}\right)$ plasma have a reducing effect on oxide species, which form in the surface layers of metal films such as Ti [15]. However, as far as TiN is concerned, hydrogen species could also have an etching effect on TiN during the first stages of crystallization. In pure Ti films, TiN only starts to crystallize at $800{ }^{\circ} \mathrm{C}$ because $\mathrm{TiSi}_{2}$ readily forms in the whole film at $600{ }^{\circ} \mathrm{C}$, which prevents TiN from crystallizing. In contrast, owing to the presence of Mo films between Ti and Si, TiN starts to crystallize at $600{ }^{\circ} \mathrm{C}$ in Mo-Ti bilayer films. The very thin and intense reflection lines at $33^{\circ}$ and $56^{\circ}$ correspond to the Si substrate.

An increase of substrate temperatures up to $800{ }^{\circ} \mathrm{C}$ results in the crystallization of $\mathrm{MoSi}_{2}$ after a plasma exposure conducted for $1 \mathrm{~h} 30 \mathrm{~min}$ (Figure 4c). Beside XRD features assigned to TiN, new reflection lines at Bragg angles equal to $26.13^{\circ}, 35.38^{\circ}, 41.18^{\circ}, 41.55^{\circ}, 45.49^{\circ}$ and $48.25^{\circ}$ correspond to the most intense (101), (102), (003), (111), (200) and (112) reflection lines of $\mathrm{MoSi}_{2}$ of hexagonal structure, respectively (JCPDS card no. 04-018-0302). The additional XRD peaks located at Bragg angles of $22.65^{\circ}, 30.10^{\circ}, 39.75^{\circ}, 44.69^{\circ}, 46.23^{\circ}$, and $57.45^{\circ}$ correspond to the most (002), (101), (110), (103), (112), and (200) reflection lines of $\mathrm{MoSi}_{2}$ of body-centered tetragonal structure (JCPDS card no. 00-041-0612). Since they are very thin and intense, $\mathrm{MoSi}_{2}$ of tetragonal structure is well-crystallized. In the same way as Ti films where strong interdiffusions of $\mathrm{Si}$ and Ti are identified at temperatures as low as $400{ }^{\circ} \mathrm{C}$, before various titanium silicides are formed at higher temperatures [15], interdiffusions of $\mathrm{Si}$ and Mo occurred at the Mo-Si interface and $\mathrm{MoSi}_{2}$ crystallizes at substrate temperatures of $800^{\circ} \mathrm{C}$. $\mathrm{TiO}_{2}$ in rutile phase is detected in the film instead of anatase phase (Figure 4c). 
Longer plasma exposures result in the growth of TiN and $\mathrm{MoSi}_{2}$ of tetragonal structure; $\mathrm{MoSi}_{2}$ of hexagonal structure is transformed into the tetragonal structure (Figure $4 \mathrm{~d}$ ). Such a phase transition has been reported in reference [5]. In this work, amorphous molybdenum silicides with $\mathrm{Si} / \mathrm{Mo}$ ratio equal to 1.9 are annealed at various temperatures for $30 \mathrm{~min}$. $\mathrm{MoSi}_{2}$ of hexagonal structure crystallizes at $600{ }^{\circ} \mathrm{C}$ and is continuously transformed into the tetragonal structure with increasing temperatures over $800^{\circ} \mathrm{C}$. However, contrasting results have been reported in other papers, especially in the case of Mo-Si multilayers. Cai et al. have only identified tetragonal $\mathrm{MoSi}_{2}$ at $900{ }^{\circ} \mathrm{C}$, whereas polycrystalline mixtures of $\mathrm{Mo}_{5} \mathrm{Si}_{3}$ and hexagonal and tetragonal phases of $\mathrm{MoSi}_{2}$ have been observed at $600{ }^{\circ} \mathrm{C}$ in other works [24]. According to the authors, the transition temperature is probably influenced by the sample deposition environment (sputtering gas, pressure ... during magnetron sputtering deposition). Chi et al. [25] showed that the formation of both hexagonal and tetragonal phases of $\mathrm{MoSi}_{2}$ is nucleation controlled. The corresponding activation energies are equal to 1.5 and $7.8 \mathrm{eV}$, respectively. So, hexagonal $\mathrm{MoSi}_{2}$ is formed as the first crystalline phase and tetragonal $\mathrm{MoSi}_{2}$ is the final. $\mathrm{No} \mathrm{Mo}_{3} \mathrm{Si}$ and $\mathrm{Mo}_{5} \mathrm{Si}_{3}$ have been identified in our work, although they should also crystallize under such conditions, according to the Mo-Si phase diagram [25]. However, the formation of a very thin layer of $\mathrm{Mo}_{5} \mathrm{Si}_{3}$ and / or $\mathrm{Mo}_{3} \mathrm{Si}$ near the Mo film cannot be ruled out.

\subsubsection{Raman Investigations}

Raman spectroscopy measurements carried out on Mo-Ti bilayer films processed at 600 and $800{ }^{\circ} \mathrm{C}$ confirm the $\mathrm{XRD}$ results (Figure 5).

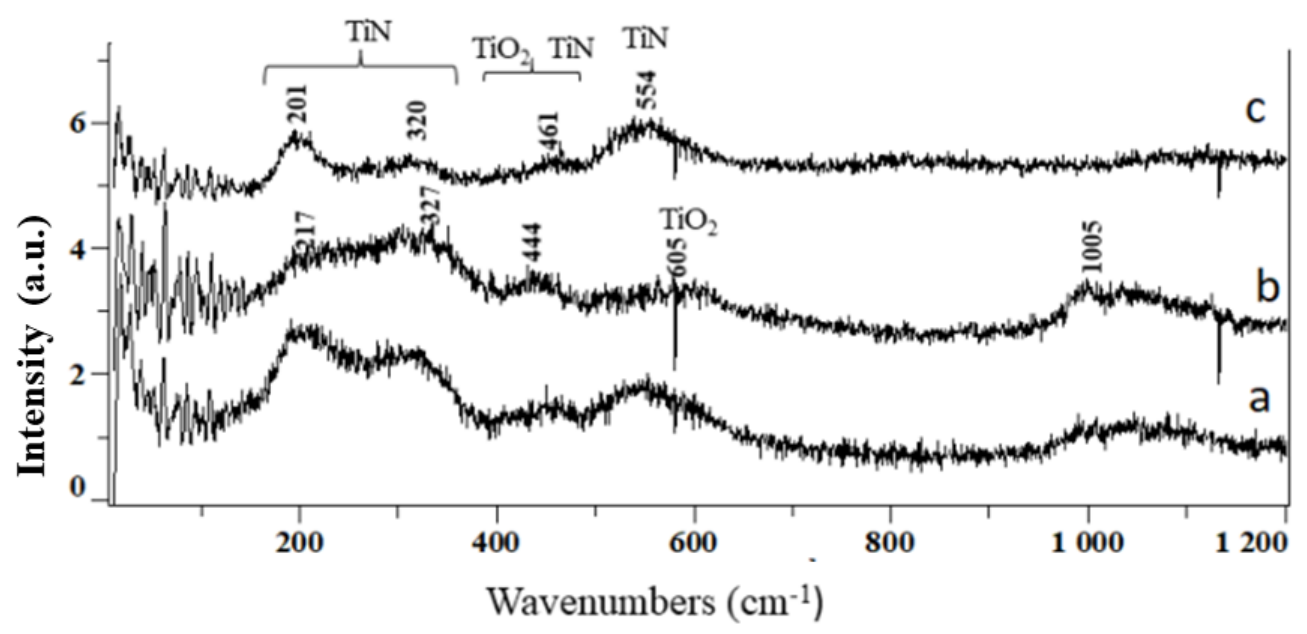

Figure 5. Raman scattering spectra of Mo-Ti bilayer films heated at $600{ }^{\circ} \mathrm{C}$ and exposed to $\left(\mathrm{Ar}-31 \% \mathrm{~N}_{2}-\right.$ $6 \% \mathrm{H}_{2}$ ) plasma for $1 \mathrm{~h} 30 \mathrm{~min}(\mathbf{a})$ and $3 \mathrm{~h}(\mathbf{b})$, heated at $800{ }^{\circ} \mathrm{C}$ and exposed to (Ar- $\left.31 \% \mathrm{~N}_{2}-6 \% \mathrm{H}_{2}\right)$ plasma for $3 \mathrm{~h}(\mathbf{c})$.

The Raman signal corresponding to the Mo-Ti bilayer film processed at $600{ }^{\circ} \mathrm{C}$ for $1 \mathrm{~h} 30 \mathrm{~min}$ is well structured and typical of the first-order Raman scattering of TiN compound (Figure 5a). TiN crystallizes in the high symmetry of B1-structured materials of $\mathrm{NaCl}$ type, which does not display any first-order Raman scattering due to the $\mathrm{O}_{\mathrm{h}}$ symmetry. However, because of the presence of point defects such as metal and nitrogen vacancies, the crystal symmetry is broken [26,27]. On Figure 5a, the Raman signal consists of two main regions of intense features, in the acoustic frequency region ranging between 200 and $350 \mathrm{~cm}^{-1}$ and in the optical frequency region ranging between 500 and $600 \mathrm{~cm}^{-1}$. The scattering identified in the acoustic range is assigned to vibrations of heavy Ti ions and the one in the optic range to vibrations of lighter $\mathrm{N}$ ions. Since the Raman features are rather broad, especially those located in the acoustic frequency range, TiN is amorphous or consists of small sized-crystallites. Ti oxides are also identified on Figure $5 \mathrm{a}$. The broad band located around $450 \mathrm{~cm}^{-1}$ could be a convolution of the vibrational modes of TiN at $464 \mathrm{~cm}^{-1}$ and $\mathrm{TiO}_{2}$ at $446 \mathrm{~cm}^{-1}$ whereas the 
shoulder identified at the high wave number side of TiN band, located at about $550 \mathrm{~cm}^{-1}$ is due to the presence of $\mathrm{TiO}_{2}$. $\mathrm{TiO}_{2}$ in the rutile phase usually shows the most intense $\mathrm{E}_{\mathrm{g}}$ and $\mathrm{A}_{1 \mathrm{~g}}$ modes at 446 and $612 \mathrm{~cm}^{-1}[15]$.

Longer treatment durations result in a strong decrease of the intensity of the Raman signal corresponding to TiN and especially the intensity of the transverse acoustic (TA) and optical (TO) modes at 200 and $550 \mathrm{~cm}^{-1}$, respectively (Figure $5 \mathrm{~b}$ ). This phenomenon is assigned to Raman measurements since spectra are obtained from the light scattered normal to the sample surface, which promotes the longitudinal modes. So, only the longitudinal acoustic mode at about $320 \mathrm{~cm}^{-1}$ is still identified as well as the Raman signals corresponding to $\mathrm{TiO}_{2}$. Such a strong decrease of the TiN signal has also been observed in XRD patterns and may be assigned to the etching effect of hydrogen species. Poorly crystallized compounds should be more sensitive to this effect.

It can also be noticed that both Raman spectra (a) and (b) in Figure 5 exhibit features at high wave numbers located around $1050 \mathrm{~cm}^{-1}$. The presence of such a broad band is quite surprising. Its shape is similar to the three dome-like bands, usually identified at wave numbers of about 737,848 and $947 \mathrm{~cm}^{-1}$ which correspond to Mo oxides present in Mo films [13]. Interestingly, Stampfl et al. in [28], highlighted the interaction of $\mathrm{MoO}_{3}$ with various metal oxides used for the preparation of supported Mo catalysts. Results show that the characteristic peaks in metal-oxide stretching region at 816 and $992 \mathrm{~cm}^{-1}$ disappeared. New peaks are identified in the wave numbers region ranging from 800 to $1100 \mathrm{~cm}^{-1}$, depending on the metal oxide support. To our knowledge, this is the only work reporting such phenomenon. In the light of this work, we can conclude that because of Ti-Mo interactions, mixed Ti-Mo oxides could be identified by a broad band, at wave numbers higher than the characteristic vibrational modes of Mo oxides. Further experiments are needed to confirm such a result.

The characteristic Raman scattering bands of TiN are well identified in the spectrum (c) in Figure 5, recorded on Mo-Ti bilayer films processed at $800{ }^{\circ} \mathrm{C}$ for $3 \mathrm{~h}$. The result is quite similar to the one obtained for Ti films processed under same experimental conditions [15]. TiN is well crystallized. Moreover, the second order broad bands at 825 and $1128 \mathrm{~cm}^{-1}$ are also identified. The presence of $\mathrm{TiO}_{2}$ is less pronounced than in films processed at $600{ }^{\circ} \mathrm{C}$. Except $\mathrm{TiN}$ and $\mathrm{TiO}_{2}$, no other features are identified on spectrum (c). On the assumption that the broad band located around $1050 \mathrm{~cm}^{-1}$ corresponds to mixed Ti-Mo oxides, the result shows that they are fully reduced by hydrogen species such as $\mathrm{NH}_{x}$ and $\mathrm{H}$ produced in the plasma. It is worth noting that, although $\mathrm{MoSi}_{2}$ displays two active vibrational modes $A_{1 g}$ and $E_{g}$ at 325 , and $440 \mathrm{~cm}^{-1}$, respectively [24], the spectrum (c) does not exhibit any features. They are in the same range of wave numbers as the characteristic Raman bands of TiN, which are intense after processing for $3 \mathrm{~h}$, while on the other hand the surface layer of TiN should be sufficient to block any Raman emissions from $\mathrm{MoSi}_{2}$. In what follows, the nitrogen diffusion into Mo-Ti bilayer films as well as the interdiffusion of Ti, Mo, and Si elements across Ti-Mo and Mo-Ti interfaces of Mo-Ti bilayer films heated at 400,600 and $800{ }^{\circ} \mathrm{C}$ and exposed to $\left(\mathrm{Ar}^{-} \mathrm{N}_{2}-\mathrm{H}_{2}\right)$ plasma for 1 $\mathrm{h}$ are investigated by SIMS experiments.

\subsection{Diffusion at Ti Surface and Ti-Mo and Mo-Si Interfaces}

\subsubsection{Mo-Ti Bilayer Films Processed at $400{ }^{\circ} \mathrm{C}$}

The N signal profile in Figure 6 clearly shows that nitrogen starts to diffuse into the surface layers of the Ti film at low temperature.

Nitrogen is incorporated in the surface region up to a depth of about one quarter of the thickness of Ti film. As for the untreated Mo-Ti bilayer films, both Mo-Ti and Si-Mo interfaces are well identified. The various elements contained in Mo-Ti bilayer films processed at $400{ }^{\circ} \mathrm{C}$ do not diffuse through both interfaces. The oxygen SIMS signal intensity remains high in the whole Ti film, especially in the vicinity of the surface and Ti-Mo interface. 


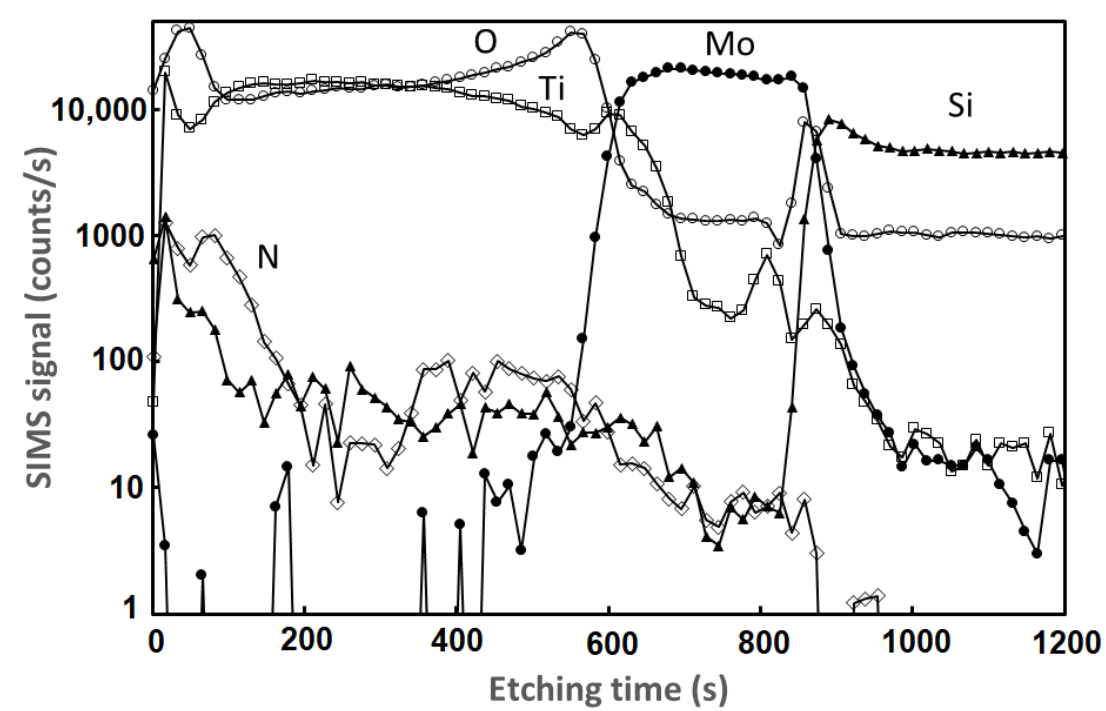

Figure 6. SIMS depth profiles of Mo-Ti bilayer film heated at $400{ }^{\circ} \mathrm{C}$ and exposed to $\left(\mathrm{Ar}-31 \% \mathrm{~N}_{2}-6 \% \mathrm{H}_{2}\right)$ plasma for $1 \mathrm{~h}$.

\subsubsection{Mo-Ti Bilayer Films Processed at 600 and $800{ }^{\circ} \mathrm{C}$}

The diffusion of nitrogen into the film greatly increases with increasing temperature. The amount of nitrogen incorporated into the surface region is greatly enhanced in Mo-Ti bilayer films processed at 600 and $800{ }^{\circ} \mathrm{C}$ (Figures 7 and 8). Interestingly, a strong depletion of oxygen SIMS intensity is observed in the first surface layers. $\mathrm{NH}_{x}$ and $\mathrm{H}$ species produced in the plasma reduce the surface oxides, which allows the transfer of nitrogen into the Ti film to be improved. Such an effect is correlated to the decrease of $\mathrm{TiO}_{2}$ amount in Mo-Ti bilayer films processed at $800{ }^{\circ} \mathrm{C}$.

Two diffusion modes are identified by the change of the slope of nitrogen signal in the surface region of Mo-Ti bilayer films processed at $600{ }^{\circ} \mathrm{C}$. It can be also noticed that $\mathrm{Si}$ starts to diffuse into the Mo film in the opposite direction with a roughly constant amount through the Mo film. This result is correlated with the formation of Mo silicides before they crystallize at higher temperature. The amount of nitrogen incorporated in the surface region of the Mo-Ti bilayer film processed at 600 and $800{ }^{\circ} \mathrm{C}$ are rather similar, but nitrogen seems to penetrate deeper into the Mo-Ti bilayer with increasing temperature.

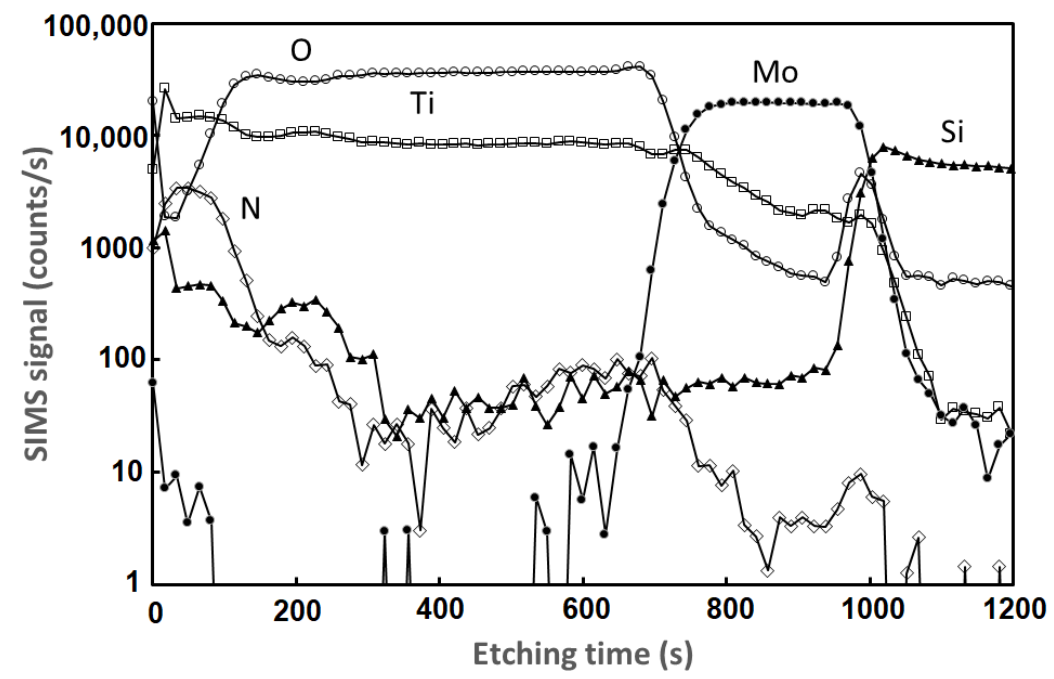

Figure 7. SIMS depth profiles of Mo-Ti bilayer film heated at $600{ }^{\circ} \mathrm{C}$ and exposed to $\left(\mathrm{Ar}-31 \% \mathrm{~N}_{2}-6 \% \mathrm{H}_{2}\right)$ plasma for $1 \mathrm{~h}$. 


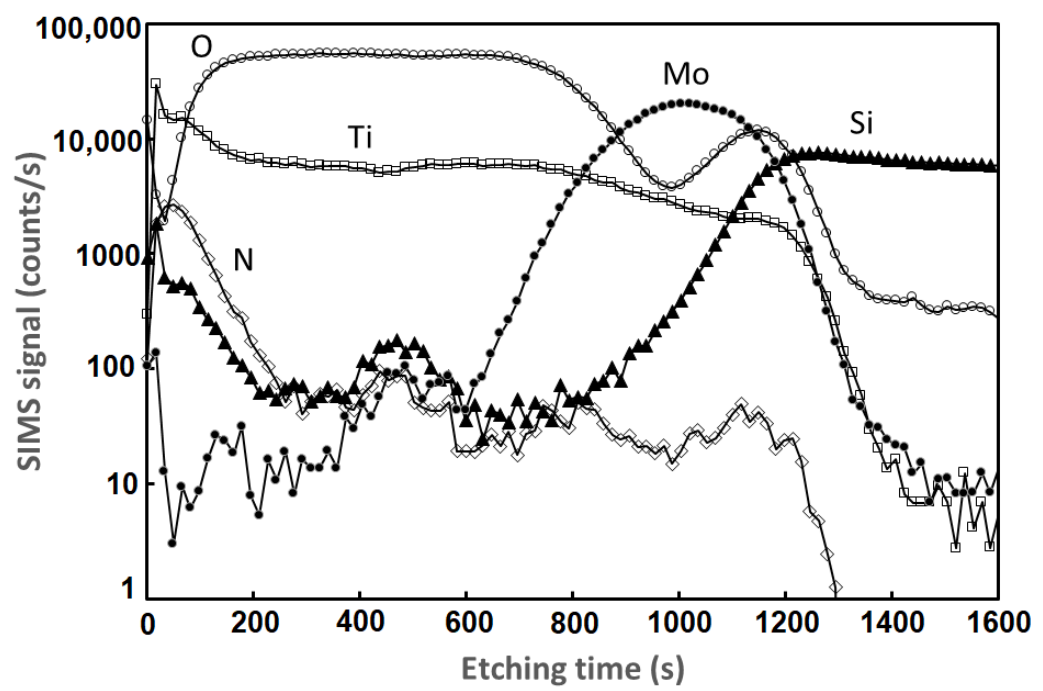

Figure 8. SIMS depth profiles of Mo-Ti bilayer films heated at $800{ }^{\circ} \mathrm{C}$ and exposed to $\left(\mathrm{Ar}-31 \% \mathrm{~N}_{2}-6 \% \mathrm{H}_{2}\right)$ plasma for $1 \mathrm{~h}$.

The change of slope in the diffusion profile of nitrogen also seen at $800{ }^{\circ} \mathrm{C}$, could correspond to additional interfaces in Mo-Ti bilayer films processed at high temperature. This result will be clarified in next sections. It is worth noting that an outstanding change in the form of the Mo signal is well identified at $800{ }^{\circ} \mathrm{C}$. The Mo-Ti interface is broader which indicates a strong interdiffusion of Mo and Ti. In the same way, Si diffuses through the whole Mo layer. This result is correlated to the crystallization of $\mathrm{MoSi}_{2}$ compounds at $800{ }^{\circ} \mathrm{C}$.

The interdiffusion of $\mathrm{Ti}, \mathrm{Mo}$, and $\mathrm{Si}$ across $\mathrm{Si}-\mathrm{Mo}$ and $\mathrm{Mo}-\mathrm{Ti}$ interfaces is also well identified in Figure 9, which displays the elemental composition of Mo-Ti bilayer films processed at $800{ }^{\circ} \mathrm{C}$ for $1 \mathrm{~h}$ 30 min, along a line scan carried out across the interfaces by EDS.

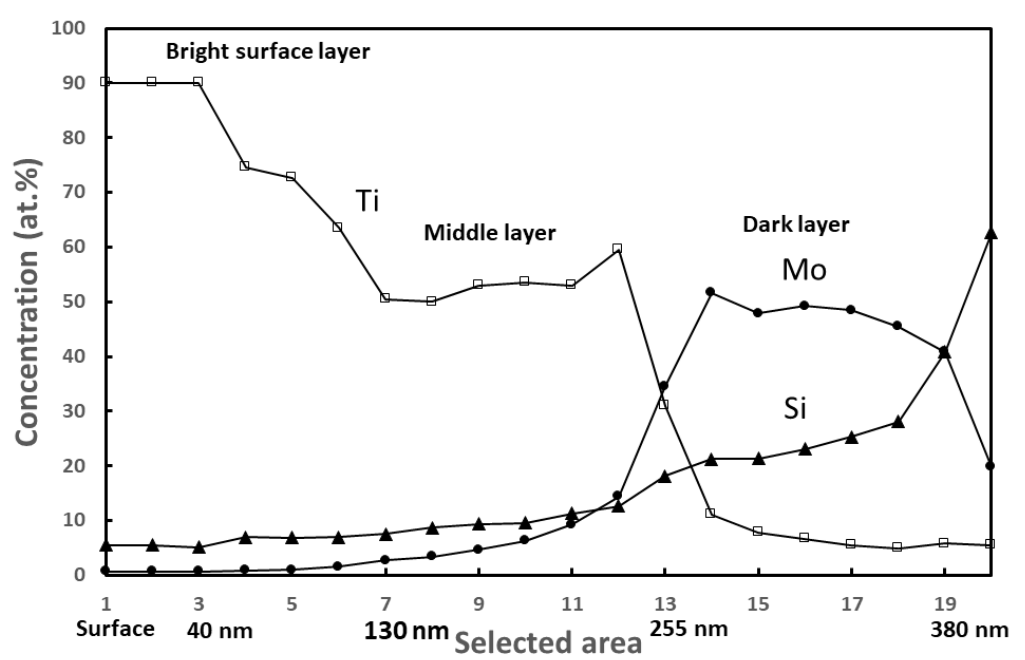

Figure 9. EDS Line scan results providing the concentration of $\mathrm{Ti}$, Mo and $\mathrm{Si}$ (at.\%) in Mo-Ti bilayer films heated at $800{ }^{\circ} \mathrm{C}$ and exposed to $\left(\mathrm{Ar}-31 \% \mathrm{~N}_{2}-6 \% \mathrm{H}_{2}\right)$ plasma for $1 \mathrm{~h} 30 \mathrm{~min}$.

The distribution of concentration of Ti from the surface up to the Mo film is identified as strongly uneven, which seems related to the formation of a heterogeneous structure in Ti films. The Ti content is constant in the first surface layers up to a depth of about $40 \mathrm{~nm}$, then decreases from the surface to 50 at. $\%$ at a depth of about $130 \mathrm{~nm}$, where it remains constant up to the Ti-Mo interface, and then strongly decreases up to about 10 at.\% in the Mo film. In the same way, Si strongly diffuses in the opposite direction through the whole Mo layer. Its content reaches a value of about 10 at.\% at the 
Ti-Mo interface, then it slowly decreases up to the surface of the bilayer film. The distribution of Mo concentration is well correlated to the corresponding Mo SIMS diffusion profile, i.e. Mo diffuses both into Ti film and Si wafer. In contrast with Si content, the Mo content is trifling in surface layers. The distribution of $\mathrm{Cr}$ and $\mathrm{Cu}$ concentration have not been reported in the figure. The presence of $\mathrm{Cr}$ and $\mathrm{Cu}$ are due to the polar piece, sample holder and grid on which the sample is deposited for TEM measurements.

\subsection{Microstructural Properties of Mo-Ti Bilayer Processed at $800^{\circ} \mathrm{C}$}

The morphology and the microstructures of Mo-Ti bilayer films are investigated by means of TEM, SAED, and SEM. The cross-sectional bright-field electron micrograph (a) of the Mo-Ti bilayer film coated on Si substrate after processing at $800{ }^{\circ} \mathrm{C}$ for $1 \mathrm{~h} 30 \mathrm{~min}$, is displayed in Figure 10.

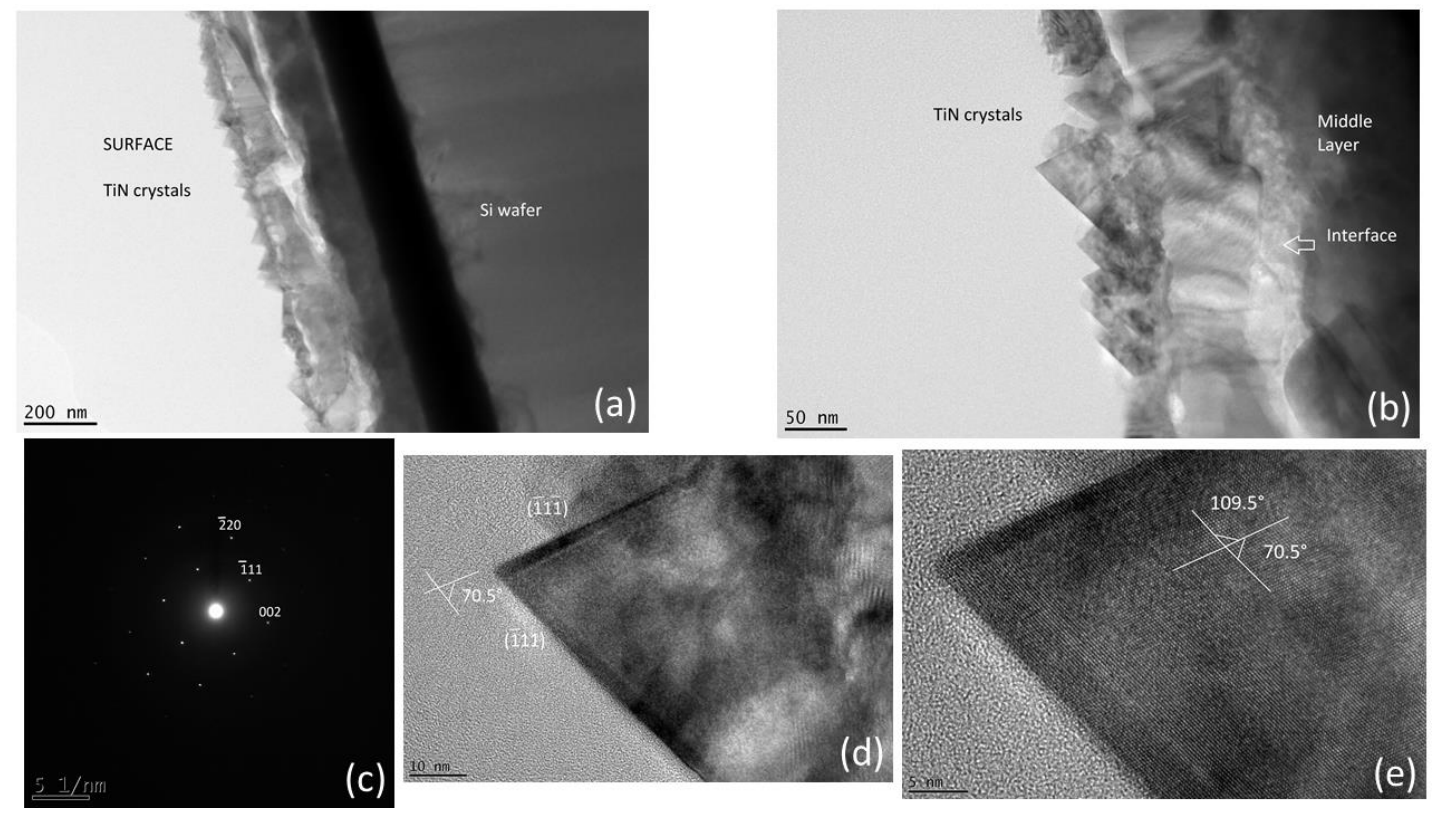

Figure 10. Cross-sectional transmission electron micrograph of the Mo-Ti bilayer film heated at $800{ }^{\circ} \mathrm{C}$ and exposed to $\left(\mathrm{Ar}-31 \% \mathrm{~N}_{2}-6 \% \mathrm{H}_{2}\right)$ plasma for $1 \mathrm{~h} 30 \mathrm{~min}(\mathbf{a}),(\mathbf{b})$. SAED pattern of TiN crystallites (c) and high-resolution TEM (HRTEM) image of TiN crystallites (d), (e). 11.

Three distinct layers of nearly equal thickness of about $150 \mathrm{~nm}$ are clearly seen. The thickness of the bilayer film is found to vary from 400 to $480 \mathrm{~nm}$. The layers exhibit three different grey tints which vary from dark to light from the Mo-Si interface up to the surface. Since Mo is the heaviest element, it absorbs more the electron beam than other elements, so the variation from dark to light grey reflects the gradient of concentration of Mo through the Mo-Ti bilayer film. The first layer located in the vicinity of the surface is rough on a micrometer scale compared with the other two layers. It is formed of two sub-layers, one consisting entirely of many square-shaped crystals ranging from about 20 to $70 \mathrm{~nm}$ wide, whereas the second one consists of rather round crystals of sizes not larger than $100 \mathrm{~nm}$ (Figure 10b). The morphology of the first layer reflects the uneven Ti distribution shown in Figure 9. The Ti content is constant in the layer consisting of square shaped crystals up to the second sub-layer and then decreases. The SAED pattern (c) in Figure 10 has been taken on the crystal (d) in Figure 10. It is identified as the TiN phase of cubic structure orientated along its [110] zone axis. TiN crystals are usually orientated along their [110] crystallographic direction, so they tend to display a flattened morphology with the [110] direction perpendicular to the flat surface. The SAED pattern (c) also shows that they are oriented along their [-220] crystallographic direction in the growth direction of the film. The SAED pattern (a) in Figure 11 has been taken on the first layer, it is identified as a mixture of TiN phase of cubic structure and $\mathrm{MoSi}_{2}$ of hexagonal structure. 


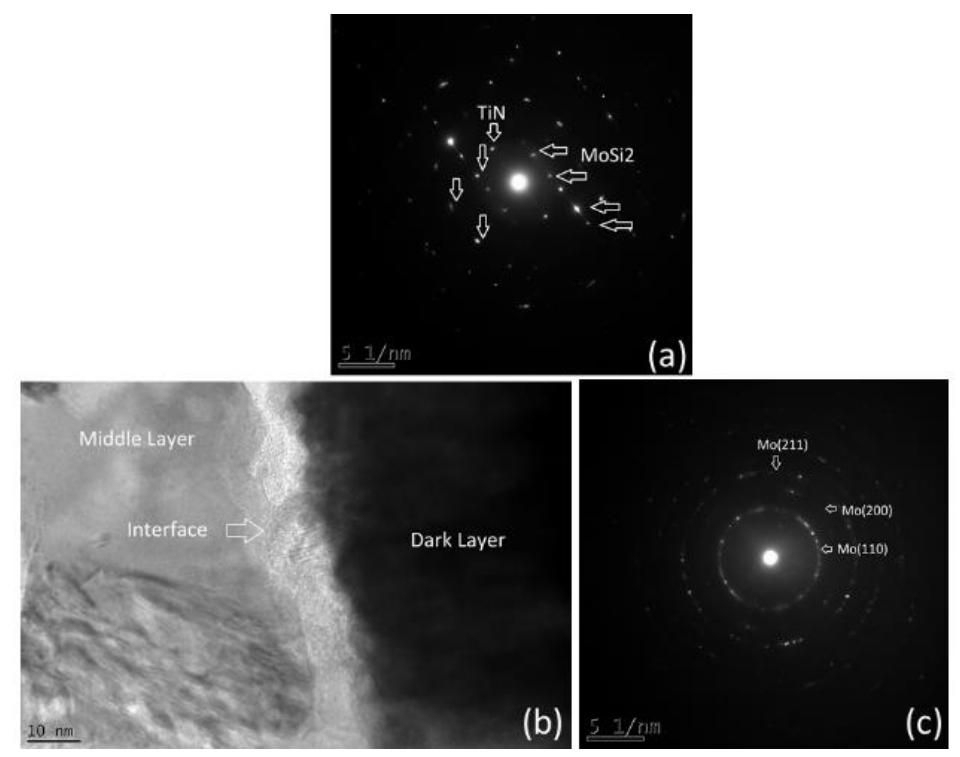

Figure 11. SAED pattern of surface layer and dark layer of the Mo-Ti bilayer film heated at $800{ }^{\circ} \mathrm{C}$ and exposed to $\left(\mathrm{Ar}-31 \% \mathrm{~N}_{2}-6 \% \mathrm{H}_{2}\right)$ plasma for $1.5 \mathrm{~h}(\mathbf{a}, \mathbf{c})$, respectively. HRTEM image of the interface between middle layer and dark layer $(\mathbf{b})$.

So, in addition to $\mathrm{TiN}, \mathrm{MoSi}_{2}$ crystallizes in the layer consisting of round crystals where a gradual decrease of Ti content has been identified by EDS. The second layer located in the middle of the Mo-Ti bilayer film also consists of round crystals of hexagonal $\mathrm{MoSi}_{2}$. The content of $\mathrm{Ti}$ through this layer is also constant, because the layer probably mainly consists of Mo-Ti alloys. In contrast, the darker layer located in the vicinity of Si wafer mainly consists of pure Mo. The columnar structure of Mo is displayed on the high resolution TEM (HRTEM) image (b) in Figure 11, and its polycrystalline structure is clearly identified on the SAED pattern (c). The interfaces between the various layers are clearly identified in Figure 10a,b and Figure 11b. They are brighter than the layers and seem to consist of a mixture of amorphous and crystallized structures of nanometric size which gives them a rough aspect on a nanometric scale (HRTEM images Figures $10 \mathrm{~b}$ and $11 \mathrm{~b}$ ). Since $\mathrm{Si}$ is more transparent in the electron beam than TiN and $\mathrm{MoSi}_{2}$, the interfaces are expected to mainly consist of $\mathrm{Si}$, which has diffused through Mo-Ti bilayer films processed at $800^{\circ} \mathrm{C}$. The morphology of Mo-Ti bilayer films processed at $800^{\circ} \mathrm{C}$ for $1 \mathrm{~h} 30 \mathrm{~min}$ consists of strongly faceted grains of nanometric size with triangular morphology, uniformly distributed over the surface of samples (Figure 12).

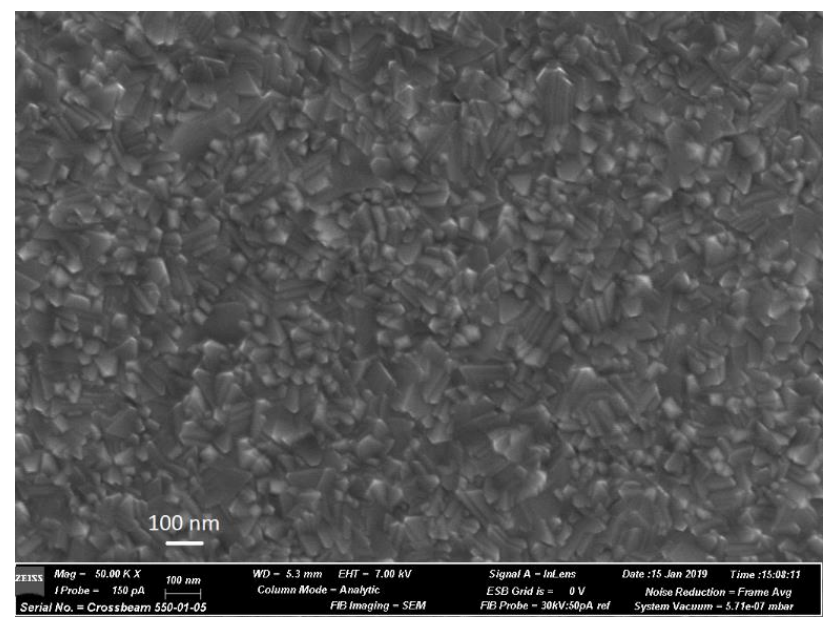

Figure 12. SEM image of the surface of Mo-Ti bilayer films heated at $800{ }^{\circ} \mathrm{C}$ and exposed to $\left(\right.$ Ar- $\left.31 \% \mathrm{~N}_{2}-6 \% \mathrm{H}_{2}\right)$ plasma for $1 \mathrm{~h} 30 \mathrm{~min}$. 


\section{Discussion}

The results reported in this paper highlight the strong ability of the components of Mo-Ti bilayer films coated on $\mathrm{Si}$ wafer to diffuse across various interfaces. The diffusion of nitrogen into the surface layers of the material heated at 600 and $800{ }^{\circ} \mathrm{C}$ and exposed to $\left(\mathrm{Ar}-31 \% \mathrm{~N}_{2}-6 \% \mathrm{H}_{2}\right)$ plasma as well as the diffusion of $\mathrm{Si}$ and $\mathrm{Mo}$ across $\mathrm{Si}-\mathrm{Mo}$ and $\mathrm{Mo}-\mathrm{Ti}$ interfaces give rise to the formation and crystallization of TiN and $\mathrm{MoSi}_{2}$, which are both thermodynamically and kinetically controlled.

Ti diffused into the whole Mo film during the synthesis of Mo-Ti bilayer by evaporation, which results in the formation of binary Ti-Mo alloys. Among them, $\mathrm{Ti}_{0.9} \mathrm{Mo}_{0.1}$ crystallizes. At the end of the evaporating process, the Mo-Ti bilayer consists of Mo, Ti-Mo alloys, and $\mathrm{Ti}$ in the form of $\mathrm{TiO}_{2}$ of amorphous structure. Ti reacted with oxygen which was incorporated during the evaporating process. It is well known that $\mathrm{Ti}$ strongly reacts with oxygen; the enthalpy of formation of $\mathrm{TiO}_{2}$ is equal to $-944 \mathrm{~kJ} \cdot \mathrm{mol}^{-1}$ at room temperature [29], compared with those of $\mathrm{MoO}_{2}$ and $\mathrm{MoO}_{3}$ which are equal to $-598.94 \mathrm{~kJ} \cdot \mathrm{mol}^{-1}$ and $-745.05 \mathrm{~kJ} \cdot \mathrm{mol}^{-1}$, respectively [30]. $\mathrm{TiO}_{2}$ crystallizes in Mo-Ti bilayer films processed in expanding plasma at 600 and $800{ }^{\circ} \mathrm{C}$. The anatase phase is the predominant form at $600{ }^{\circ} \mathrm{C}$, and it turns into the rutile phase at higher temperatures. Owing to the reducing effect of gaseous species produced in $\left(\mathrm{Ar}-\mathrm{N}_{2}-\mathrm{H}_{2}\right)$ plasma and especially $\mathrm{NH}_{x}$ and $\mathrm{H}$, oxide species amount tends to decrease with increasing treatment duration. Hydrogen species play an important role in the reduction of remaining oxides. They also prevent the formation of oxides, which come from oxygen or water adsorbed on the wall of the reactor and added to the plasma. Oxides contained in the surface layers form a barrier of diffusion which prevents nitrogen diffusion. The enthalpy of the formation of $\mathrm{TiN}$ is very low compared with the one of $\mathrm{TiO}_{2}$. The value is equal to $-338 \mathrm{~kJ} \cdot \mathrm{mol}^{-1}$ [29]. So, hydrogen species allow the barrier of the diffusion of oxides to be reduced and promote the formation of TiN. The oxygen content is trifling in the first layers of Mo-Ti bilayer films, which only consist of TiN crystals. The occurrence of exothermic chemical reactions between the plasma and the surface of the metal has been evidenced during the formation of Mo nitrides [13]. These properties make the plasma expanding process very different from sputtering or implantation processes where the impinging ions of high energy plays the main role. In the same way as Ti films, nitrogen starts to diffuse into the surface layers of the metal, at a low temperature of about $400{ }^{\circ} \mathrm{C}$, from $\mathrm{NH}_{x}$ species produced in the plasma which react at the metal surface. TiN starts to crystallize at $600{ }^{\circ} \mathrm{C}$ in Mo-Ti bilayer films in contrast with Ti films which are fully transformed into $\mathrm{TiSi}_{2}$ after processing at $600{ }^{\circ} \mathrm{C}$ for $30 \mathrm{~min}$. $\mathrm{TiSi}_{2}$ prevents TiN from crystallizing at temperatures lower than $800{ }^{\circ} \mathrm{C}$ [15]. The TiN layer consists of small crystals of nanometric size oriented along their [-220] crystallographic direction in the growth direction of the film. In the opposite direction of nitrogen diffusion, silicon starts to diffuse from the Mo-Si interface through to the Mo layer at $600{ }^{\circ} \mathrm{C}$. At $800^{\circ} \mathrm{C}$, Si and Mo diffuse up to the surface, $\mathrm{MoSi}_{2}$ crystallizes in hexagonal structure in the vicinity of TiN crystals, and then continuously transformed into $\mathrm{MoSi}_{2}$ of tetragonal structure for longer treatment durations. It is worth noting that crystals of $\mathrm{MoSi}_{2}$ also exhibit nanometric dimensions in the vicinity of TiN crystals after plasma processing for $1 \mathrm{~h} 30 \mathrm{~min}$. The enthalpy of formation of $\mathrm{MoSi}_{2}$ at $25^{\circ} \mathrm{C}$, equal to $-137 \mathrm{~kJ} \cdot \mathrm{mol}^{-1}$ [31], is slightly lower than the one of $\mathrm{TiSi}_{2}$. Owing to the strong interdiffusion of various elements across the interfaces and the formation of TiN and $\mathrm{MoSi}_{2}$ crystallized phases, the Mo-Ti bilayer films heated at $800{ }^{\circ} \mathrm{C}$ and processed for $1 \mathrm{~h} 30 \mathrm{~min}$ exhibits very heterogeneous structures. Three layers of nearly equal thickness with clear interfaces have been identified, as well as additional interfaces in the surface layers. The gradual conversion of $\mathrm{TiSi}_{2}$ into TiN phase has been successfully evidenced in Ti films exposed to (Ar- $\mathrm{N}_{2}-\mathrm{H}_{2}$ ) expanding plasma and has been related to the reaction between $\mathrm{TiSi}_{2}$ and nitrogen on $\mathrm{TiSi}_{2}$ surface and grain boundaries. Si released during the reaction moves towards Si substrate, where it epitaxially crystallizes [14]. So, further investigations on the development of Mo-Ti bilayer films during plasma processing would improve the understanding of the structural properties of $\mathrm{TiN}^{\mathrm{N}}$ and $\mathrm{MoSi}_{2}$ and the reaction at interfaces. The influence of gaseous species produced in $\left(\mathrm{Ar}-\mathrm{N}_{2}-\mathrm{H}_{2}\right)$ plasma on the formation of nitrides would be studied in the case of Mo-Ti bilayer films. A reduction-nitridation process has been evidenced during the nitriding process of Mo thin films with the formation of the 
high temperature $\mathrm{Mo}_{2} \mathrm{~N}$ phase [13]. A better understanding of the growth process of these compounds could be interesting, since $\mathrm{TiSi}_{2}$ and TiN exhibit low resistivity equal to 15 and $30 \mu \Omega \cdot \mathrm{cm}$, respectively whereas $\mathrm{MoSi}_{2}$ of hexagonal structure is a narrow gap semiconductor with a band gap of $0.035 \mathrm{eV}$ [32]. This value has been mainly investigated by density functional theory [33-35] and also by valence band X-ray photoelectron spectroscopy [35].

\section{Conclusions}

An expanding plasma process carried out on Mo-Ti bilayer films heated at $800{ }^{\circ} \mathrm{C}$ resulted in the formation of a very heterogeneous structure arising from the diffusion of nitrogen into surface layers on one hand, and strong interdiffusions of $\mathrm{Ti}, \mathrm{Mo}$, and $\mathrm{Si}$ through interfaces on the other hand. Nitrogen starts to diffuse at $400{ }^{\circ} \mathrm{C}$, whereas $\mathrm{Si}$ and Mo start to diffuse at $600^{\circ} \mathrm{C}$. TiN crystallites of nanometric size are identified at $600{ }^{\circ} \mathrm{C}$ and $\mathrm{MoSi}_{2}$ crystallites of nanometric size form at $800{ }^{\circ} \mathrm{C}$ in the surface layers. Further investigations carried out on Mo-Ti bilayer films processed for longer treatment durations could improve the comprehension of mechanisms involved in the growth of both nitrides and silicides. Moreover, since TiN is a good conductor and $\mathrm{MoSi}_{2}$, a good semiconductor, electrical conductivity measurements will be performed.

Author Contributions: Conceptualization, I.J. and J.L.J.; Methodology, I.J., A.B.; Validation, A.B., J.L.J., I.J.; Formal Analysis, I.J.; Investigation, R.M., J.C., P.C., D.M., A.B., A.P.; Data Curation, I.J. and R.M.; Writing-Original Draft Preparation, I.J.

Funding: This research received no external funding.

Acknowledgments: We thank Therèse Merle-Méjean for helpful discussions. Région Limousin is acknowledged for the support of work on the surface reactivity.

Conflicts of Interest: The authors declare no conflict of interest.

\section{References}

1. Oyama, S.T. Introduction to the chemistry of transition metal carbides and nitrides. In The Chemistry of Transition Carbides and Nitrides, 1st ed.; Oyama, S.T., Ed.; Springer: Dordrecht, The Netherlands, 1996; pp. 2-10.

2. Jauberteau, I.; Bessaudou, A.; Mayet, R.; Cornette, J.; Jauberteau, J.L.; Carles, P.; Merle-Méjean, T. Molybdenum nitride films: Crystal structures, synthesis, mechanical, electrical and some other properties. Coatings 2015, 5, 656-687. [CrossRef]

3. Ponon, N.K.; Appleby, D.J.; Arac, E.; King, P.J.; Ganti, S.; Kwa, K.S.K.; O’Neill, A. Effect of deposition conditions and postdeposition anneal on reactively sputtered titanium nitride films. Thin Solid Films 2015, 578, 31-37. [CrossRef]

4. Bhaskaran, M.; Sriram, S.; Short, K.T.; Mitchell, D.R.G.; Holland, A.S.; Reeves, G.K. Characterization of C54 titanium silicide thin films by spectroscopy, microscopy and diffraction. J. Phys. D Appl. Phys. 2007, 40, 5213-5219. [CrossRef]

5. Yanisagawa, S.; Fukuyama, T. Preparation of molybdenum silicide films by reactive sputtering. J. Electrochem. Soc. 1980, 127, 1120-1124. [CrossRef]

6. Lima, L.P.B.; Diniz, J.A.; Doi, I.; Fo, J.G. Titanium nitride as electrode for MOS technology and Schottky diode: Alternative extraction method of titanium nitride work function. Microelectron. Eng. 2012, 92, 86-90. [CrossRef]

7. Wang, L.-L.; Peng, W.; Jiang, Y.-L.; Li, B.-Z. Effective Schottky barrier height lowering by TiN capping layer for $\mathrm{TiSi}_{x} /$ Si power diode. IEEE Electron Device Lett. 2015, 36, 597-599. [CrossRef]

8. Pshyk, A.V.; Kravchenko, Y.; Coy, E.; Kempinski, M.; Iatsunskyi, I.; Zaleski, K.; Pogrebnjak, A.D.; Jurga, S. Microstructure, phase composition and mechanical properties of novel nanocomposite (TiAlSiY)N and nano-scale (TiAlSiY)N/MoN multifunctional heterostructures. Surf. Coat. Technol. 2018, 350, 376-390. [CrossRef]

9. Ting, Y.-J.; Lian, K.; Kherani, N. Fabrication of titanium nitride and molybdenum nitride for supercapacitor electrode application. ECS Trans. 2011, 35, 133-139. [CrossRef] 
10. Xie, Y.; Tian, F. Capacitive performance of molybdenum nitride/titanium nitride nanotube array for supercapacitor. Mater. Sci. Eng. B 2017, 215, 64-70. [CrossRef]

11. Blösch, P.; Güttler, D.; Chirila, A.; Tiwari, A.N. Optimization of Ti/TiN/Mo back contact properties of $\mathrm{Cu}$ (In,Ga)Se 2 solar cells on polyimide foils. Thin Solid Films 2011, 519, 7453-7457. [CrossRef]

12. Li, W.; Yan, X.; Aberle, A.G.; Venkataraj, S. Effect of a TiN alkali diffusion barrier layer on the physical properties of Mo back electrodes for CIGS solar cell applications. Curr. Appl. Phys. 2017, 17, 1747-1753. [CrossRef]

13. Jauberteau, I.; Mayet, R.; Cornette, J.; Bessaudou, A.; Carles, P.; Jauberteau, J.L.; Merle-Méjean, T. A reduction-nitridation process of molybdenum films in expanding microwave plasma: Crystal structure of molybdenum nitrides. Surf. Coat. Technol. 2015, 270, 77-85. [CrossRef]

14. Jauberteau, I.; Carles, P.; Mayet, R.; Cornette, J.; Bessaudou, A.; Jauberteau, J.L. Competing growth of titanium nitrides and silicides in Ti films processed in expanding microwave plasma: Morphology and microstructural properties. AIP Adv. 2018, 8, 095105. [CrossRef]

15. Jauberteau, I.; Mayet, R.; Cornette, J.; Mangin, D.; Bessaudou, A.; Carles, P.; Jauberteau, J.L.; Passelergue, A. Silicides and nitrides formation in Ti films coated on $\mathrm{Si}$ and exposed to $\left(\mathrm{Ar}-\mathrm{N}_{2}-\mathrm{H}_{2}\right)$ expanding plasma. Coatings 2017, 7, 23. [CrossRef]

16. Xin, C.; Liu, W.; Li, N.; Yan, J.; Shi, S. Metallization of $\mathrm{Al}_{2} \mathrm{O}_{3}$ ceramic by magnetron sputtering Ti/Mo bilayer thin films for robust brazing to Kovar alloy. Ceram. Int. 2016, 42, 9599-9604. [CrossRef]

17. Ruzic, J.; Emura, S.; Ji, X.; Watanabe, I. Mo segregation and distribution in Ti-Mo alloys investigated using nanoindentation. Mater. Sci. Eng. A 2018, 718, 48-55. [CrossRef]

18. Fan, J.; Lu, M.; Cheng, H.; Tian, J.; Huang, B. Effect of alloying elements Ti, Zr, on the property and microstructure of molybdenum. Int. J. Refract. Hard Mater. 2009, 27, 78-82. [CrossRef]

19. Kislitin, S.B.; Potekaev, A.I.; Uglov, V.V.; Klopotov, A.A.; Klopotov, V.D.; Ivanov, Y.F.; Parpiev, A.T. Steel suface TiCrN, TiMoN coatings structural phase state change features after low-energy alpha particles irradiation. IOP Conf. Ser. Mater. Sci. Eng. 2018, 289, 012010. [CrossRef]

20. Oliveira, N.T.C.; Aleixo, G.; Caram, R.; Guastaldi, A.C. Development of Ti-Mo alloys for biomedical applications: Microstructures and electrochemical characterization. Mater. Sci. Eng. A 2007, 452, 727-731. [CrossRef]

21. Simka, W.; Krzakala, A.; Korotin, D.M.; Zhidkov, I.S.; Kurmaev, E.Z.; Cholakh, S.O.; Kuna, K.; Dercz, G.; Michalska, J.; Suchanek, K.; et al. Modification of a Ti-Mo alloy surface via plasma electrolytic oxidation in a solution containing calcium and phosphorus. Electrochem. Acta 2013, 96, 180-190. [CrossRef]

22. Zhang, W.-D.; Liu, Y.; Wu, H.; Song, M.; Zhang, X.-D.; Lan, X.-D.; Yao, T.-H. Elastic modulus of phases in Ti-Mo alloys. Mater. Charact. 2015, 106, 302-309. [CrossRef]

23. Gu, M.; Bai, S.; Xia, X.; Huang, X.; Li, X.; Shi, X.; Chen, L. Study of the high temperature interfacial stability of $\mathrm{Ti} / \mathrm{Mo} / \mathrm{Yb}_{0.3} \mathrm{Co}_{4} \mathrm{Sb}_{12}$ thermoelectric joints. Appl. Sci. 2017, 7, 952. [CrossRef]

24. Cai, M.; Allred, D.D. Raman spectroscopic study of the formation of $t-\mathrm{MoSi}_{2}$ from Mo/Si multilayers. J. Vac. Sci. Technol. A 1994, 12, 1535-1541. [CrossRef]

25. Chi, E.; Shim, J.; Kwak, J.; Baik, H. Silicide formation by solid-state diffusion in Mo/Si multilayer thin films. J. Mater. Sci. 1996, 31, 3567-3572. [CrossRef]

26. Constable, C.P.; Yarwood, J.; Münz, W.D. Raman microscopic studies of PVD hard coatings. Surf. Coat. Technol. 1999, 116, 155-159. [CrossRef]

27. Stoehr, M.; Shin, C.-S.; Petrov, I.; Greene, J.E. Raman scattering from $\operatorname{TiN}_{x}(0.67<x<1.00)$ single crystals grown on $\mathrm{MgO}$ (001). J. Appl. Phys. 2011, 110, 083503. [CrossRef]

28. Stampfl, S.R.; Chen, Y.; Dumesic, J.A.; Niu, C.; Hill, C.G., Jr. Interactions of molybdenum oxide with various oxide supports. Calcination of mechanical mixtures. J. Catal. 1987, 105, 445-454. [CrossRef]

29. Barhai, P.K.; Kumari, N.; Banerjee, I.; Pabi, S.K.; Mahapatra, S.K. Study of the effect of plasma current density on the formation of titanium nitride ant titanium oxynitride thin films prepared by reactive DC magnetron sputtering. Vacuum 2010, 84, 896-901. [CrossRef]

30. Birtill, J.J.; Dickens, P.G. Thermochemistry of hydrogen molybdenum bronze phases $\mathrm{H}_{x} \mathrm{MoO}_{3}$. J. Solid State Chem. 1979, 29, 367-372. [CrossRef]

31. O'Hare, P.A.G. Thermodynamic properties of silicides. III. Specific energy of combustion in fluorine of a hyperstoichiometric disilicide. The standard molar enthalpy of formation $\Delta_{\mathrm{f}} \mathrm{H}_{\mathrm{m}}^{\circ}$ of $\mathrm{MoSi}_{2.067 \pm 0.002}$ at the temperature 298.15 K. J. Chem. Thermodyn. 1993, 25, 1333-1343. [CrossRef] 
32. Ohishi, Y.; Kurosaki, K.; Suzuki, T.; Muta, H.; Yamanaka, S.; Uchida, N.; Tada, T.; Kanayama, T. Synthesis of silicon and molybdenum-silicide nanocrystal composite films having low thermal conductivity. Thin Solid Films 2013, 534, 238-241. [CrossRef]

33. Shugani, M.; Aynyas, M.; Sanyal, S.P.; Rajagopalan, M. Electronic properties of MoSi 2 . Indian J. Pure Appl. Phys. 2013, 51, 634-637. (In English)

34. Mattheiss, L.F. Calculated structural properties of $\mathrm{CrSi}_{2}, \mathrm{MoSi}_{2}$ and $\mathrm{WSi}_{2}$. Phys. Rev. B 1992, 45, 3252-3259. [CrossRef]

35. Pankhurst, D.A.; Yuan, Z.; Nguyen-Manh, D.; Abel, M.-L.; Shao, G.; Watts, J.F.; Pettifor, D.G.; Tsakiropoulos, P. Electronic structure and bonding in $\mathrm{MoSi}_{3}, \mathrm{Mo}_{5} \mathrm{Si}_{3}$ and $\mathrm{Mo}(\mathrm{Si}, \mathrm{Al})_{2}$ alloys investigated by $\mathrm{X}$-ray photoelectron spectroscopy and density-functional theory. Phys. Rev. B 2005, 71, 075114. [CrossRef]

2019 by the authors. Licensee MDPI, Basel, Switzerland. This article is an open access article distributed under the terms and conditions of the Creative Commons Attribution (CC BY) license (http://creativecommons.org/licenses/by/4.0/). 